\title{
Culture in the System of Being as a Problem of Phil Osophical Knowledge
}

\author{
Natalya Rinatovna Balynskaya
}

\author{
Svetlana Nikolayevna Amelchenko
}

Nosov Magnitogorsk State Technical University, 38 Lenin Ave., Magnitogorsk, 455000, Chelyabinsk Region, Russia

\author{
Doi:10.5901/mjss.2015.v6n5s4p289
}

\begin{abstract}
The issue of studying culture within the system of being is preconditioned by ambiguous approaches to understanding these universal notions throughout the history of philosophic ideas. Such approaches frequently limit the parameters of these notions. The goal of this article is to reveal unique features of the culture and complex system of its interaction with the system of being. This article covers the ontologic status of culture, correlation of the material, ideal, and social in its universe. System, structural and functional methods, as well as the developing modeling method, exemplified by the philosophic concept of M. S. Kagan, is applied to study this issue more thoroughly. In addition, some provisions of his theory, as well as the modeling methods, can be further developed and complemented, while certain assumptions can be reconsidered allowing to make additional adjustments to the formation of objective knowledge about culture. This article analyzes the structural components of the ontologic system, including the being of the objective and individualized ideality, which was not specified by M.S. Kagan. It showed that this structural subdivision of the being produces ideas, ideals, and goals of a person and the society, being the main source of culture origins and development, the characteristic of its above-biological status in the universe, and the source of intelligent and value-oriented development. This article also reveals the culture as a complex system characterized by diversity of existence and the structure of being. However, culture is not only a part of the system of being; it also determines its diversity through the unique specifics of its forms and functional processes.
\end{abstract}

Keywords: philosophy, culture, the being, system, the material, the ideal, the social, human

\section{Introduction}

Each cognitive process becomes more productive if the studied object is considered not separately, but in the context of all constituent parts of being, stipulating and predetermining its essence in one way or another.

The notion of "being" designates the past, current, and future existence, reflecting the reality in the infinite manifold of its manifestations. A particular feature of this inexhaustible universe was considered by various representatives of philosophic knowledge as the fundamental characteristic resulting in varying interpretations of the semantic content of this notion. From metaphysic points of view, the being obtained such attributes as eternity and permanence (Parmenides), from the dialectic point of view, its main characteristics were motion and transformation (Heraclitus). Idealistic philosophy considered the being as the true origin of the universe (Plato et al.), materialistic philosophy considered it as the nature in consistent development of intrinsic physical, organic, and other elements (Democritus, Marxist philosophy).

In case of such unidirectional understanding, an analysis of culture in the system of being could show it in a limited format, or it might become impossible, since the culture is syncretic, polymodal, and cross-functional phenomenon that cannot be reduced to spirit or matter. In the 20th century, the constraints of the former epochs were overcome, as exemplified by the statement of $\mathrm{N}$. Hartmann who said that we should avoid a single-sided approach to this issue, when one definition "sticks to the sense, spirit, ideas, and God, and the other -to the matter, laws of nature, and causality; one spiritualizes the matter and nature, and the other relegates the spirit to an appendix of matter.

In addition to the comprehensive coverage of the concept of "being," clarification of the specific features of these phenomena allows to approach the understanding of the status of culture in an ontologic system. For a long period, the culture was considered as the area of absolute values, ideals, and spiritual qualities of an individual. This description originates from the German classical philosophy and can be represented by the following statement of I. Kant: "It (Culture) is the ability of a human being to use the natural disposition for reason to act upon his or her natural desires" (Kant, 1966).

Meanwhile, the philosophical interpretation of this phenomenon also underwent significant changes, with the 
begging of such changes set by the works of the representatives of the philosophy of life in particular. Thus, W. Dilthey argued that the foundations of culture are economy, forms of human intercourse, the law and the state (Dilthey, 1995). Tendency for enhancement of the notion of "culture" was continued with further development of the philosophic thought and can be supported by the definition of V. S. Stepin, who developed "an understanding of culture as complex system of above-biological programs of human life-sustaining activity (activities, behavior and communication of people)" (Stepin, 2010). Explaining his position, he refers the whole variety of "knowledge, regulations, norms, skills, ideals, activity and behavior types, ideas, beliefs, goals, value orientations" to the notion of culture, which together form the continuously accumulating and developing social experience (Stepin, 2010).

The culture shall be considered as the aggregate of method and results of human life-sustaining activity, forming in accordance with the historically developing norms, knowledge, values, and ideals. The culture represents symbolicfigurative and axiological universe, obtaining objectification in various fields of human activities. All its forms and processes are included in the system of being, however this issue remains poorly developed and covered by philosophic literature. Meanwhile, as mentioned by M. V. Mezhuyev, philosophy is capable to consider the specific features of culture in its universality, covering the major fundamental problems: "Philosophy does not explore the culture in its versatile manifestations, but substantiates the possibility of its existence in the world" (Mezhuyev, 2006). Conducting study in this regard allows showing more precisely the essence of culture, its status in the system of being, and forces facilitating its formation and historic development.

\section{Literature Review}

As it has already been mentioned, the infinite diversity of the current reality preconditioned the appearance of various approaches to interpretation of the "being" notion. E. Durkheim was one of those who decided to expand ontology onto the social area, and named it as the "reality of specific kind," the "specific kind of being." He claimed the following: "We assimilate the reality of the social world with the realities of the external world. This means... not to relegate the higher forms of being to the lowest forms, but, alternately, to reclaim that the former obtain the level at least equal to the one the latter have" (Durkheim, 1995). In his concept, the specific form of being was represented by the aggregate of social connections and relations, institutional organization of all areas of human life-sustaining activity.

Another form of being was associated with the human existence. The works of N.A. Berdyayev, M. Heidegger, E. Fromm and others revealed the exceptional status of humans. In particular, N.A. Berdyayev argued that personality with spiritual dimension cannot be opposed to the cosmic and social universe as a whole, since integrity given from within is inherent for individuality. Therefore, "being a personality means being one's own self" in conjunction with others, experiencing the commonness of destiny (Berdyayev, 1993). Heidegger mentioned the fact that the form of being, which reveals itself in existence-the discovery of the sense of being in "physical presence," co-existence with the world, in the glimpse of being-is the form of being inherent for humans only (Heidegger, 2011).

E. Fromm found specific reality in the unique human experience. He argued that the "mode of being" outlined by him have the following prerequisites: independence, freedom, and critical thinking (Fromm, 2009). In this regard, the specific feature of human being manifests itself in creative self-organization, the ability to reveal the value of personal talents in the process of fruitful interaction with other people.

These forms of being, along with the material being of the nature, formed the background of cultural studies in the M. S. Kagan's system of being. He was the first Russian philosopher who outlined this issue and applied the cultural modeling method in the system of being, having enhanced the philosophic knowledge base related to this phenomenon. The modeling method applied in conjunction with other methods allows building the consistent, illustrative, and comprehensive understanding of the culture universe. In addition, the methods for philosophic perception of culture have specific features, which require further consideration.

\section{Methods}

Methodology development plays a fundamental role in any cognition process, including gnoseology of culture. Its methodological base was established in the works of W. Dilthey, the author of "Introduction to the Human Sciences." In this work, he mentioned the difference between the natural science that uses the explanation method for natural phenomena, and the cognition of culture, which he understood as the world spiritualized by human activities, including religion, culture, politics, law, etc. Dilthey argued that "Spiritual science does not just study the existing things, but represents a conscious system of value judgements and imperatives, including values, ideals, norms, orientations, images of the future" (Dilthey, 2000). 
Considerable contribution to the development of methodology for studying culture was made by neo-Kantians, who separated the natural world from the world of freedom, the main feature of which was the ability of a person to make a choice without external impact. W. Windelband, one of the founders of the Neo-Kantianism Baden School, demarcated the application fields of the nomothetic approach that generalizes all the consistently recurrent in natural environment, and the ideographic approach that allows not only to reveal the unique features of culture, but to show the meaning of universal norms, values, and ideals, which are understood by a person and community as "the highest point of cultural development" (Windelband, 1995).

A representative of Neo-Kantianism, H. Rickert contributed to the development of methodological tooling for culture cognition. His work "Natural and cultural sciences" lay the foundation for classification of natural and human sciences. He also noticed that natural sciences use the generalization method revealing universal development laws, while cultural sciences apply the individualization method discovering generally valid issues in a unique combination of empirical facts and social-moral relations (Rickert, 1998).

Meanwhile, the methodology proposed by W. Dilthey, W. Windelband, and $\mathrm{H}$. Rickert admitted subjectivism in interpretation of cultural phenomena that discredited scientific status of the obtained knowledge. The general point of their works was that explanation determines the methodology for exact and natural sciences, while cognition of culture is based on understanding. However, according to P. Ricoeur, "understanding without explanation is blind, as much as explanation without understanding is empty" (Ricoeur, 1995).

Within the wide panorama of philosophical cognition of culture, formed in the modern times, many trends revealing its essence developed their own methodological basis. Complexity of culture's universe preconditioned the necessity to introduce various cognition methods that should be as rigorous as the methods of exact sciences (Amelchenko, 2012). This kind of methodology includes the system, structural, functional, topological, and modeling method.

Thus, the system method is used for studying the internal structure of the cognition object, determination of all its components, and discovering specific features in general. This method allows to reveal constituent differences of cultural subsystems and the structure of culture as an integral formation through studying its material, social, and spiritual components, accepted behavior models, etc.

The structural method is developed to study the internal structure of the cognition object, determination of all component parts and discovering specific features in general. This method allows to reveal the constituent differences of cultural subsystems and the structure of culture as an integral formation through studying its material, social, and spiritual components, accepted behavior models, etc.

The functional method reveals the designations of the object and all its constituent parts. The goal of this method is to expose the tasks resolved in the process of activities and development.

The topological method allows determining significant modifications (varieties) of an object, grouping such modifications and carrying out their systematization.

The modeling method is applied for illustrative representation of structural features of the considered object, essential connections and functional relations between the constituent parts. This method comprehensively approaches the study of a certain object and considers the object as an integral system with a number of functioning subsystems.

M.S. Kagan effectively applied the modeling method to demonstrate the place of culture in the system of being. However, certain provisions of his theory, as well as the modeling methods, can be further developed, improved and reconsidered, thus allowing to making additional adjustments to the formation of objective knowledge about culture.

\section{Results}

The philosophic concept of M. S. Kagan for the first time raised the question of the status of culture in the system of being, and proposed the new modelling method that had never been applied before for more precise explanation of the considered issue. 


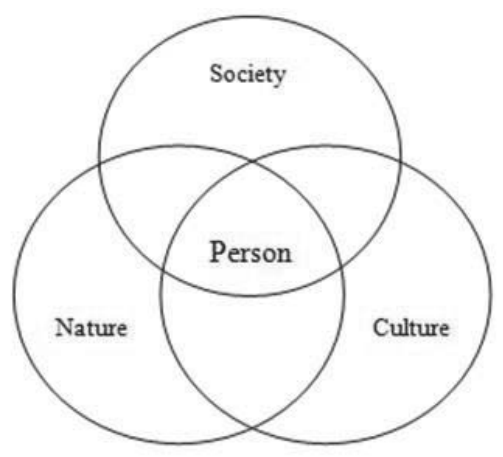

Figure 1. The philosophic concept of M. S. Kagan

The content of his theory resides in the following assumptions: nature is the first form of existence; the second form of being appears at a certain stage of its development. This form is society, as the beyond-nature means of communication between people in the course of their life and activity; the third form of being is the human-the central element among all main forms of being; and the fourth form of being is the culture, as the beyond-nature means of transferring behavior programs, and the mechanism of social inheritance. Description of this concept was followed by the scheme illustrating three intersect circles representing the being of nature, society, and culture. The area where they intersect represents the being of human (Figure 1) (Kagan, 1996).

Having revealed the structure and diversity of the forms of being, Kagan managed to show the culture as an integral part of the whole, seamlessly connected with the being of nature, society, and human. However, some assumptions of his theory require adjustment and elaboration.

In the first instance, Kagan's theory lines up a sequence of specific forms of being (society, person, culture), while formation of these phenomena is a simultaneous process. Establishment of social connections and separation of the human from the animal-biological environment was intimately associated with cultural creative activity, as mentioned in works by Alain de Benoist, P. A. Sorokin, and many others.

Secondly, notwithstanding the conventionality of this scheme, its logics admits existence of a certain part of the society beyond culture, as well as development of a considerable cultural environment beyond the society. This condition is in contradiction with Kagan's theory, which states that the culture covers the entire life of the society, forms social relations equaling to the society in scale. Other famous theorists also argued about the inseparable unity of culture and the society: F. Tenbruck called this unity "seamless connection" (Tenbruck, 1990), and P. A. Sorokin claimed that personality, the society, and culture are parts of the inseparable trine, and none of its elements can exist without the others (Sorokin, 1992; Sorokin, 2006).

While these two clarifications are of technical nature and take into account the fact that Kagan's model is designed to resolve a certain task-illustration of the forms of being irrespective of their interrelation, the third clarification is about the fundamental issue not related to Kagan's form of being that presupposes reconsideration of separate provision of his theory.

\section{Discussion}

\subsection{Vulnerability of M. S. Kagan's Theory}

Kagan's scheme representing the system of being shows that culture is only partially immersed into the nature and extends beyond its limits. This method might indicate a special form of being, which represents ideas appearing in human mind, senses, meanings, and values raising above the material, which is its medium, but having unique features. Absence of ideal being in Kagan's concept proved that his views were formed in the tideway of the Marxist-Soviet type materialistic philosophy claiming that being is the reality existing beyond and independently from human consciousness. The priority value in this case was given to the material factor. Though the Marxist philosophy asserted that the material and economic basis is the determinant factor for the development of culture and the progress driver, Kagan, under condition of failure of this system of views, assumed that the entire human history develops chaotically, by trial and error, 
and has no certain reference points (Kagan, 1996).

In addition, the ability to understand the actual state of affairs, critically analyze it, set goals, and build a sequence of activities to achieve such goals means that a person becomes a subject of culture, while culture differentiates itself from other processes and phenomena, which take place in the natural biological environment and depend on casual connections without any cognitive and/or creative idea or plan. As mentioned by N. Tomashvili, the essence of a human reveals itself in thoughts, the ability to "make decisions and a conscious choice "(Tomashvili, 2010). Consequently, it is possible to get closer to understanding of the specifics of culture and its ontologic status, having taken into account all available forms of being with continued importance for culture.

\subsection{Approaches to Understanding the Content of Being}

Resolving this task becomes possible due to the unique flexibility and mobility of human thinking, which is raising to a high level of abstraction and outlining various "worlds" and "regions" within the universe. For example, E. Husserl noted that a "region is nothing but an aggregate related to certain concrete, the highest level of generic unity," and that a "material thing" and "soul" are the different regions of being (Husserl, 2009). Turning attention to such regions of being as nature, society, cogitative structures (mathematics, logics, etc.), he considered them as the aggregate of various objects forming the world of possible experience obtained within the framework of regional ontology.

$\mathrm{N}$. Hartmann provided evolved systematization of ontology and showed being as the reality having four levelsphysically material, organically living, mental, and spiritual. All the three levels that are built over the first one are carried by the previous levels depending on their laws; however, they have only inherent features extrinsic for the reality of the lower order. The highest level of being became possible due to the appearance and complication of physical, organic, and psychical reality, but the uniqueness does not originate from it and is determined by its own representation rules. The spiritual reality includes the logic of laws, forms of perception, art, religion, and many other things. Herewith the imperatives, ideals, and values appear to combine the individual and public conscience (Hartmann, 2003). The abovementioned clarifies connection between being and culture.

\subsection{Modeling Culture in the System of Being}

According to V. A. Lektorskiy, the most important task of philosophy is to find a "relation between these worlds" and to "construct bridges between them" (Lektorskiy, 2012). Based on the above, being should be considered as a system including the following subsystems:

1) Material being, the being of objects and processes, which covers the following:

a) The immense nature, the variety of its phenomena, stems, and processes;

b) Objects and processes made by the human from substance and energy of the natural environment and delegated with social and historic characteristics.

2) Ideal being, which appears on the higher stage of the nature development, formed by:

a) Public conscience creating an objectified view of the ideal-axiological fields represented by natural and specialized languages, as well as ideals, values, norms, etc.;

b) Hman conscience represented by the aggregate of thoughts, beliefs, emotions, etc., creating an individualized form of the ideal being.

3) Social being consisting of:

a) Bbeing of the society in its institutional structure and organizational-historical development;

b) Individual being of the human included into public life and having socio-historical characteristics.

4) Human being is a dialectic unity of the natural and the social, the physically finite and the spiritually infinite.

Culture forms in aggregate unity with the society's being that is based on the material being of objects and processes, immersed into and transforming the nature. Herewith, the society uses the essence and energy from environment (level $1 \mathrm{a}$ of being) to create material culture (level $1 \mathrm{~b}$ ) determining its characteristics (level $3 a$ ) in the processes of social and historic development.

The society and culture cannot exist beyond the objectively forming ideal being that represents the symbolicfigurative and axiological systems (level 2a), where we can observe sociocultural establishment and spiritual development of the entire society and each person in particular (levels $2 b$ and $3 b$ of being).

It is known that the universal may exist only through the singular, and the singular may exist in a way that leads to the universal. Therefore, the human existing in the material form of a physical body (level 1a), forming an individualized type of ideal being in mind (level 2b), residing in the historically formed structure of the society (level 3b), representing the 
inseparable synthesis of the material, the social, and the ideal, preserving uniqueness and relative freedom in the being of other universal systems (the 4th level) is the core of the cultural system.

The below diagram (Figure 2) represents culture in the system of being (Amelchenko, 2012).

Application of the system method to build the diagram in Figure 2 shows that culture is an aggregate of historically developing methods and results of the society and human's existence on the material and ideal levels of being. The initial basis and prerequisite for the culture being is the natural space and biological body of the human. The culture forms in nature's lap aiming at the development and creation of conditions for physical survival of humans. In addition, culture is an above-nature phenomenon consisting of the ideal semantic content of human's being including lingual, value-related, and other symbolic-figurative systems.

Culture can be formed only in a society, penetrating into all kinds of life-sustaining activity, while a society cannot exist and develop beyond the system of ideals, senses, norms, values, etc. represented in various forms of social activities. Culture and the society represent inseparably associated spheres of conscious and organized human existence. Herewith, the society is a historically developing system of connections and relations formed between people; it is an institutional form of life-sustaining activity. Culture represents implementation of ideals, goals, and values spread over time and space, assigning various meanings to the being of the entire society and each human.

\subsection{The Structure of Culture in the System of Being}

The integral unity of the modeling and system methods can be complemented by using the structural and functional methods. In the culture's universe, each individual is an actor performing certain social functions on the one hand (family, professional, and other roles), and the holder of cultural qualities on the other hand (knowledge, ethic norms, aesthetic sense, etc.), allowing him to become a single subject of cultural creativity.

On the one hand, a social group represents itself as an institution forming certain connections and relations, and on the other hand-as a group of individuals with common goals, values and ideals allowing them to become specific subjects of culture.

At one point, a society is a sophisticated system of functioning and interacting social institutions. Alternately, it is a carrier of spiritual unity and inherent creative identity as the general subject of culture.

The human community represents itself as an aggregate of institutionally organized nations and peoples. On the other way around, the human society is a universal generic subject of culture, a creator of ethnic and national cultures.

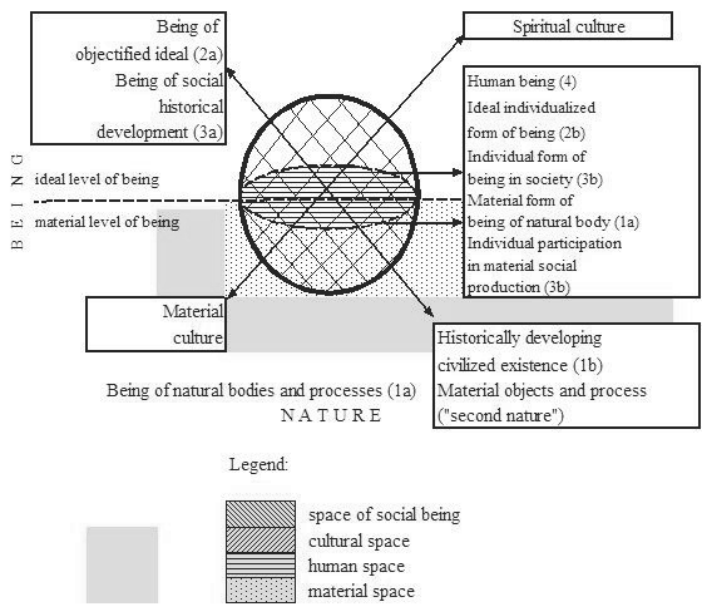

Figure 2. Place of culture in the system of being.

The specifics of the system formation provided here resides in the dialectic difference and equivalence of all designated phenomena, each of which is represented both as a subject that uses its essential forces, and as an exposed object. Dialog is fruitful interaction between various subjects that facilitates positive changes in their being. It allows enriching the 
content of culture, revealing new dimensions, and enhancing development spheres.

\subsection{Modeling the Structure of Culture in the System of Being}

Formation and development of culture occurs in dialectic interaction of the subjective and the objective, the individual and the social, the material and the ideal. The main structural components of culture within the system can be represented in a schematic form (Figure 3).

Spiritual culture of a human and a society expressed in the form of art, moral and legal norms, religious ideals, scientific discoveries, and political goals is formed at the level of ideal being by means of public and individual (relatively independent) conscience.

Industrial and technical, as well as physical processes of public and individual life that form the content of material culture, the entire artificial world of objects and phenomena created by humans are based and implemented at the level of material being.

Material culture is submerged into the nature and formed by various objective-modifying types of activities. However, it contacts the spiritual culture and is determined by cognitive, value-oriented, and projective types of activity becoming an objective representation of the above-nature essence of people, their knowledge, ideas, goals, tasks, and perceptions about suitable and necessary things. Domination of certain values and their choice becomes the basis for formation of a certain type of culture determining its uniqueness in general view of the world culture.

Outlining the ideal level of being within this model of culture points out a unique segment, where goals are set, decisions are made, and responsibility is taken for consequences of certain activities. Human ability to determine the significance and meaning of spiritual values and ideals, to strive for their implementation in various areas of activities becomes the basis of true progress, the source of culture formation and its harmonious development.

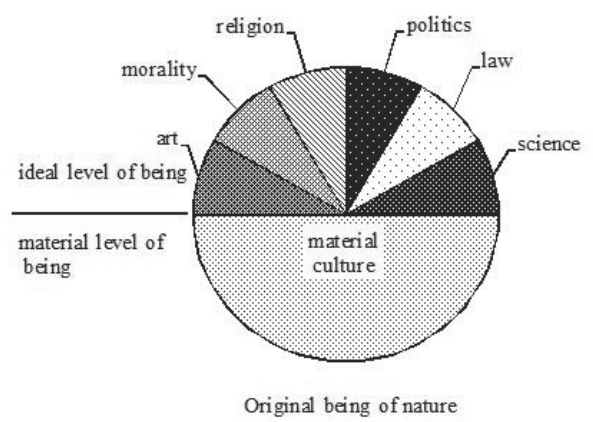

Figure 3. The structure of culture

\section{Conclusion}

Summarizing the above-mentioned, we should remember that the place of culture in the system of being represents a complex theoretical issue, which has no simple solution in modern philosophic literature. Analysis of this issue leads to understanding of dialectic relation between the culture and the system of being, all forms of which determine the possibility of existence of culture. Herewith, such structural components as the ideal, the social, and the human can be represented and developed only through the being of culture. Culture is not only a part and unique form in the system of being, but it predetermines its diversity though the specifics of its forms and processes. In addition, the spiritual component is the most important one for the being of culture- "the world of states of consciousness" intimately associated with the world of the "objective content of thinking," which was considered in works of K. Popper (Popper, 1983). The ideal form of being determines the unique specifics of culture not allowing to turning into the mode of existence of highly organized population. Finally, morality plays the dominating role in the spiritual field of culture that, according to $U$. Okeja, allows the humankind to respond ethically to the globalization issues and maintain its abovebiological status, the specific nature of which requires further study. Therefore, culture is a specific phenomenon of the system of being, the uniqueness of which is determined by its spiritual, and, in the first instance, moral component. 


\section{References}

Amel'chenko, S. N. (2012). Modeling as a Tool of Ontology and Epistemology of Culture. Philosophy and Culture, 6(54), 19-30.

Berdyayev, N. A. (1993). About the purpose of person (Author's speech, articles by Gaidekno, P. P., comments by Medvedeva, R. K., p. 123). Moscow: Pespublika.

Dilthey, W. (2000). Introduction to human sciences. In A. V. Mikhailova, \& N. S. Plotnikova (Eds.), Collected edition (Vol. 1, pp. 272-709). Moscow: Tti Kvardrata.

Dithey, W. (1995). Types of worldviews and their identification in metaphysical systems. In S. Y. Levit (Ed.), Cultural studies of the 20th century: Anthology (pp. 213-256). Moscow: Yurist.

Durkheim, E. (1995). Sociology: Subject, method, purpose (A. B. Hofmann, Trans., p. 8). Moscow: Kanon.

Fromm, E. (2009). Forgotten Language. To Have or to Be? (p. 305). Moscow: AST.

Hartmann, N. (2003). About basic foundation of ontology (Y. V. Medvedeva, Trans., pp. 87-97). Saint Petersburg: Nauka.

Hartmann, N. (1995). The problem of spiritual existence. Research for justification of the philosophy of history and the human sciences. In S. Y. Levit (Ed.), Cultural studies of the 20th century: Anthology (pp. 608-648). Moscow: Yurist.

Heidegger, M. (2011). Being and Time (V. V. Bibikhina, Trans., p. 11). Moscow: Akademicheskiy Proekt.

Husserl, E. (2009). Ideas about pure phenomenology and phenomenological philosophy (A. V. Mikhailova, Trans., p. 61). Moscow: Akademichesliy Proekt.

Kagan, M. S. (1996). Philosophy of culture) p. 416 .(Saint Petersburg: Petropolis LLP TK.

Kant, I. (1966). In V. F.Asmus, A. V. Gulyga, \& T. I. Oiserman (Eds.), Critique of Judgment (Vol. 5, pp. 161-530). Moscow: Mysl.

Lektorskiy, V. A. (2012). Philosophy, knowledge, culture (p. 8). Moscow: Kanon+ROOI Rehabilitation.

Mezhuyev, V. M. (2006). The idea of Culture. Essays on the Philosophy of Culture (pp. 11-12). Moscow: Progress-Traditsiya.

Okeja, U. (2011). Global ethic as a response to the clash of cultures. Philosophy, Culture, and Traditions, 7, 63-70.

Popper, K. (1983). In N. Sadovskiy (Ed.), Logic and the growth of scientific knowledge: Selected works (N. Sadovskiy, Trans., pp. 439440). Moscow: Progress.

Ricoeur, P. (1995). Hermeneutics. Ethics. Politics (p. 128). Moscow: "Academia" Publishing Center.

Rickert, G. (1998). In A. F. Zotova (Ed.), Natural and cultural sciences (A. F. Zotova, Trans., pp. 75-78). Moscow: Respublika.

Sorokin, P. A. (2006). Social and cultural dynamics (V. V. Sapova, Trans., p. 435). Moscow: Astrel.

Sorokin, P. A. (1992). In A. Y. Sogomonov (Ed.), Person. Civilization. Society (A. Y. Sogomonov, Trans., pp. 218-219). Moscow: Politizdant.

Stepin, V. S. (2010). Science and philosophy. Philosophy Issues, 8(66), 58-75.

Tenbruck, F. H. (1990). Representative Kultur, Sozialstruktur und Kultur (pp. 24-37). Hrsg. H. Hafertkamp. Franktfurt am Main: Suhrkamp.

Tomashvili, N. (2010). Critical Thinking as an Essential Characteristic of Man, Culture \& Philosophy. A Journal for Phenomenological Inquiry. Washington. D. C. USA; Tbilisi, Georgia, 217 p. - P. 327.

Windelband, W. (1995). Collected Works. Spirit and Time (p. 54). Moscow: INION. 